\title{
ON SOME APPLICATIONS OF \\ THE COPYING OR TRANSFER PRINCIPLE IN THE PRODUCTION OF WOODEN ARTIOLES.
}

A distinguishing characteristic of the arts and manufactures of the present century as compared with those of the past consists in the application of the principle of machine copying, in contradistinction to dependence on the skill of the operative, in the production both of the ordinary articles of commerce and of the munitions of war. Engineers are so familiar with this principle in their every day pursuits, that it frequently escapes their notice; yet a closer inspection will show that almost all machines that are intended to change the form of materials are constructed on some modification of this principle, of having the form in some way or other contained in the apparatus, with the specific object of imparting that form to the materials under operation; and it will generally be found that every process which is done well, and which at the same time is done cheaply, is performed by some skilfully arranged development of this principle. The advantage of keeping first principles steadily in view in practical applications of science is generally conceded: the knowledge of facts is considered good; but to know the law of the facts is considered better, and much more likely to hasten onwards their more extended application. A complete exposition of the various applications of this copying principle in the several arts and manufactures of the world would form a highly interesting and valuable volume.

Within the last few years a remarkable change has taken place in this respect. With regard to the tools of the smithery, production by the hammer and hand of the smith is fast giving place to production by means of apparatus constructed upon the copying or transfer principle: such as dies under the American drop hammer, the steam hammer, and the forging machine ; the employment of rolls containing on their surfaces the pattern of what is wanted; and the use of oscillating dies imparting the form to the red hot mass upon a.moving table. In each case it is seen that the general tendency is to obtain 
the form and dimensions of the article produced by the transfer of both from an apparatus prepared with care ; and to dispense with that care in the future actual production. The moulding operations of the foundry are pre-eminently copying; or, if it is attempted to analyse the recent improvements in the moulding of wheels, shells, railway chairs, and such articles, it will be found that all are designed with a view to have the accuracy and perfection of form provided in the apparatus, from which it is then transferred to the sand without so much skill being required on the part of the workman who performs the ramming of the mould. The other workshops of the engineer present that invaluable development of the copying principle termed the slide rest, assuming every variety and modification in the several machines used for turning, boring, drilling, planing, or shaping. The same principle in combination with circular cutters affords the machinery of the Small Arm Factory, the endless variety of which would alone form an interesting subject.

The object of the present paper is to give a description of a few applications of the copying principle in the production of certain articles mostly in connexion with the simple operations of wood-turning, which have been more immediately brought under the notice of the writer; and although they are trifles in themselves, still it is only by each one making a small contribution from time to time that the improvements in the details of the several workshops can be made generally known to one another.

During a short professional tour in the United States in 1854, the writer was much struck with the many simple and ingenious contrivances there introduced, in order to apply the copying principle in connexion with ordinary hand-lathe operations, where generally in this country more would be dependent upon the skill or attention of the turner or upon special machinery. For example, in the production of articles where there is repetition and which are to be turned in a common lathe, the application of certain very simple additions tends greatly to facilitate the operation and to enable the operator to dispense with the usual measuring and gauging and the use of callipers, which generally occupies so much time. 
A simple arrangement of a copying lathe is shown in Fig. 1, Plate 56. At the front of the lathe and parallel with the piece of wood A to be operated upon, there is fixed a straight edge B made of hard wood, with the upper or straight edge slightly hollowed. At the back of the lathe there is a similar fixture $\mathrm{C}$, only the upper edge is not straight but resembles the irregular form of the required article. The gouge or turning instrument $D$, instead of being held in the hand of the turner over a rest, is fixed into a piece of wood $\mathrm{E}$, the arrangement slightly resembling that of a carpenter's plane, having one end adapted to slide firmly on the straight edge $B$ at the front of the lathe, while the other is adapted to trace the irregular line $\mathrm{C}$ running along the back. In order that the workman may gradually reduce the wood to the proper diameter without the risk of digging into the mass and thereby breaking the cutting instrument, a small wedge of wood $\mathrm{F}$ is attached by a loop to the little finger of his right hand, and at the commencement of the operation is inserted between the toolholder $\mathbf{E}$ and the irregular pattern $\mathbf{C}$ at the back of the lathe, but is gradually withdrawn as the article approaches the required diameter; and at the last a finishing tool is slowly and carefully drawn along the two guides $\mathrm{B}$ and $\mathrm{C}$, thus producing the exact pattern without any effort, and in much less than half the time in which it could be done in the common way.

On a similar plan to the foregoing but differently arranged is the American system of turning long poles of small diameter, as shown in Fig. 2, Plate 56. The wood $G$ to be turned is first cut by a circular saw into square rods of the required length; these are then placed between the centres of a turning lathe, with the corners still upon them. The toolholder or cutting apparatus $\mathrm{H}$ slides steadily upon two parallel straight edges I I placed respectively at the front and back of the lathe : this toolholder consists of a metal socket $\mathrm{H}$ having cutting gouges $K$ and $\mathrm{L}$ at each end ; the foremost gouge $K$ is set to reduce the square rod to the internal diameter of the socket $H$, in order to obtain perfect steadiness; while the second or finishing gouge $L$ is set to reduce the pole to the required diameter. To relieve the workman from the trouble of pushing the socket $\mathbf{H}$ with its cutting tools along the lathe, the interior of the socket is made with 
a screwed surface; and the first gouge $K$ being set to give a tight fit, the thread which is thus formed upon the wood draws the socket along; and as the second gouge $\mathrm{L}$ is close to the hinder end of the socket, the thread does not make its appearance, being cut off by the second gouge, which is set to give the proper finished diameter to the work. In turning long small poles of an irregular figure, the second tool $\mathrm{L}$ is not a fixture upon the socket, but is held in a toolholder having one end hinged upon the socket while the other traces the required pattern placed alongside, thus causing the tool to rise or fall as it slides along the pattern.

It may be mentioned that the American wood tnrners use a centre which is not common in this country; and having been introduced into the Royal Arsenal with great advantage, its general application can be recommended. This lathe centre, which is shown in Fig. 3, Plate 56, instead of having the ordinary sharp point, is formed at the extremity with a hollow cup M, surrounded by a sharp circular edge; this when pressed into the revolving wood forms a hard centre within itself, by compression of the wood within the conical cup, which is better adapted both to retain the oil and also to continue uninjured during a long period.

The method of turning the Sabots or blocks of wood which are attached to round shell, as performed in the arsenal at Woolwich, affords another illustration of the successful application of the copying principle. Hitherto these articles have been produced by the wood turner with the gouge, chisel, and gauges, in the usual manner; it was a monotonous and very laborious process, and a skilled workman could produce only about fifty of them per day.

By the new method, the wood is first cut out of the plank into circular pieces by means of an ordinary trepanning tool, costing for wages an average of $7 d$. per hundred. The wooden disc is then perforated by a drilling machine, in order to prepare it for being screwed upon the face plate of a turning lathe.

The first turning process is to form the exterior surfaces ; and for that purpose the wood is screwed upon the centre screw of the face plate, as shown at A, Fig. 6, Plate 57. The tools or gouges $\mathrm{B}$ and $\mathrm{C}$ 
that are required to produce the form are contained on separate sliding rests $D$ and $E$ combined together upon one saddle $F$, both being actuated by the movement of a single handle $G$. The saddle $F$ itself is made to slide upon the lathe bed in the ordinary manner, by means of a rack and pinion, and is moved by the left hand of the workman by means of the handle $H$.. The dimensions of the sabot are determined by a stop upon the lathe bed against which the saddle $\mathrm{F}$ is pressed, and also by the adjustment of the gouges.

The next and last operation is to hollow the sabot for the reception of the shell. For this purpose a similar lathe is employed, shown in Fig. 7, Plate 58 ; the block $A$ is held in a universal chuck adapted to the article. The required hollow being part of a true circle, the gouge $B$ is fixed upon a holder which is capable of turning on its axis by means of a handle $\mathrm{O}$; the radius of the circle described by the gouge depending on the distance at which its cutting edge is set from its centre of motion. The toolholder is mounted upon the saddle D of a lathe, as in the former operation, the depth to which the hollow is cut being determined by a stop fixed upon the lathe bed and adjusted with reference to the face plate. In performing the operation the workman moves the saddle $\mathrm{D}$ with his left hand by a rack and pinion by means of the handle $\mathbf{E}$, while with the other hand he gently moves the handle $\mathrm{C}$ of the toolholder, making the gauge describe an are of a circle.

It will thus be seen that no skill is required during any of the producing operations, and that the form and dimensions of the article are in each case contained in the apparatus. To make sabots of other forms, the several slide rests are readjusted upon the saddle. The saving in wages effected by these arrangements amounts to more than four fifths of the original cost.

For another but smaller class of articles of similar shape, of which three or four hundred thousand are required daily, a different modification of the principle of copying is employed. The conical plug of the Minie bullet is made of box wood by self-acting machinery. In this manufacture the conical form of the plug is contained in a revolving cutter which is fixed in a lathe spindle and driven at a high velocity. 
The wood having been first cut up into long square rods by means of cireular saws, one of the wooden rods is fixed upon the lathe saddle and pushed forward against the cutter ; this gives a conical form to the end of the rod, which is then cut off by means of a circular saw, forming a plug of the required shape and dimensions.

The machinery for effecting this object is variously arranged; one of the best combinations is shown in Fig. 9, Plate 59. The headstock containing the cutter A, shown full size in Fig. 10, in addition to the revolving motion of the spindle has a longitudinal movement imparted to it by means of the grooved cam $\mathrm{B}$ and the lever $\mathrm{C}$; the wooden rod to be cut $\mathrm{D}$ being held firmly by the saddle $\mathrm{E}$, the headstock and cutter are gently pushed against its extremity, thus forming the conical end to the rod, and are then withdrawn again.

The second operation is to cut off the plug. To accomplish this the bed and saddle $\mathrm{E}$ carrying the wooden rod $\mathrm{D}$ are placed upon the top of a rocking frame, which also is moved by a cam $F$ and connecting rod $G$ but in a direction at right angles to the sliding motion of the headstock. When the conical end has been formed and the headstock drawn back, the woodholder $\mathrm{E}$ is pushed tansversely against the circular saw $\mathrm{H}$, and the finished plug drops into a box $\mathrm{I}$; after which the saddle $\mathbf{E}$ is brought back into line with the headstock, and an intermittent self-acting feed motion $K$ pushes the rod of wood forward into the position for forming another plug.

In some of the earlier machines the saw made a transverse movement to cut off the plug; by that arrangement the plugs and the chips were mixed together in the same heap, and the labour for their separation cost more than for the manufacture; but by the new arrangement, the plugs and the chips are kept separate and the cost in wages is thereby reduced more than one half.

A modification of the copying principle employed in a machine for forming square holes or mortices in wood is another example.

It consists of a combination of a square box-chisel with a screw augur working within it, shown in Figs. 4 and 5, Plate 56. The chisel $\mathrm{N}$ forms a square socket of the same external dimensions as the required mortice, having its four cutting sides chamfered inwards. 
Within this chisel and combined with it there is a revolving screw augur $O$ having an independent circular motion, its cutting edge being flush with that of the chisel. The action of the machine consists in forcing the square chisel against the wood with a pressure sufficient to make an incision, and the augur drills out about $\mathrm{g}$ ths of the required hole, the chisel making the round hole square, and with its bevilled edges pushing the chips against the running augur, by means of which they are withdrawn.

The Blanchard turning lathe contains a modification of the copying principle, susceptible of endless application in the production of irregular forms; it is used in turning gun stocks, spokes of wheels, shoe lasts, busts, and similar articles.

It may be described as two lathes placed side by side and parallel with each other, as shown in Fig. 8, Plate 58; the one lathe containing the pattern F, the other the lump of material $G$ out of which the article is to be formed, and both lathes having the same motion. The sliding rest which holds the turning tool $\mathbf{H}$ also carries a dumb instrument $I$ for tracing the pattern $F$, and by means of a weight or spring this tracer is kept in contact with the pattern. As usually constructed the turning tool $\mathrm{H}$ consists of a revolving wheel, having its periphery fitted with cutters, and driven by an independent strap at about 2000 revolutions per minute. The tracer $I$ is also of the same external circular shape and size as the tool, and is capable of turning freely on its axis. The action of the machine consists in imparting to the cutter $\mathrm{H}$ the motion of the tracer $\mathrm{I}$, as produced by the irregular surface of the pattern $\mathrm{F}$; the tracer being in contact with the pattern, as the latter turns round the tracer moves out and in accordingly; and as the material $G$ in the second lathe has the same motion as the pattern, and the cutter has the same outside form as the tracer, it necessarily produces the same shape as the pattern; and the slide rest that carries the cutter and tracer being made to slide along in the usual manner brings out the required copy of the pattern, one man being able to attend on several machines.

The Blanchard lathes employed in the workshops of the war department are variously constructed : in some the cutter and tracer 
are both mounted on a transverse slide rest; in some they are suspended like a pendulum; in another, which is found to be a very superior arrangement, the tracer and cutter are mounted together on a rocking frame, the centre of motion being near the floor. By both the latter modifications the friction is greatly reduced, and the action is more delicate in tracing the exact outline of the pattern than with the slide rest motion.

A wheel fitted with cutters similar to that used in the Blanchard lathe has been employed with great advantage in forming different eurres by means of a single instrument. This is done on the principle that if a piece of wood is passed under the cutting wheel in a line parallel with the axis of the wheel it will form a groove corresponding with the circle of the wheel's circumference; but if the wood is passed along the face of the cutting wheel it will produce a flat surface. Curves between these two extremes are obtained by adjusting. the apparatus to intermediate angles.

The manufacture of scabbard linings affords another illustration of this copying principle. The wood is first cut roughly into shape by means of the endless band saw. The next operation is to shape one side of the exterior surface : to accomplish this the rough piece of wood is laid in a wooden holder which is susceptible of a longitudinal movement, and which by means of guides is constrained to describe a curve the same as that of the scabbard; this movement is made under a revolving cutter having the transverse shape of the scabbard; the two combined motions produce the required form. The other side is formed exactly in the same manner, the finished side being laid in a holder of the exact form, in order to have the two sides placed exactly opposite to each other. These two operations complete the exterior. The third operation is to cut out the receptacle for the sword : the wood already shaped externally is laid in a holder into which it fits firmly, this holder being made to move in the proper curve under a revolving cutter the shape of the sword. It is then placed in a fourth holder over a circular saw to widen the upper end in order to receive the thick part of the sword; after which the end is laid under a circular knife having a vertical movement by means of which the point is cut 
to the proper shape. The accuracy of manufacture by this method is of course greatly superior as compared with the system of hand labour by means of which they have been made hitherto; also the rapidity of manufacture is greatly increased, two boys being able to produce 500 scabbard linings daily.

The same combination of movements is frequently arranged in a different manner, by means of which mouldings or such work can be formed on the edge of irregular surfaces. The circular cutter of the required form is placed on the top of a vertical revolving spindle, as shown at A, Figs. 11 and 12, Plate 60. The piece of wood $B$ to be operated upon is fixed to a holder $\mathrm{C}$ which has been cut to the shape in the longitudilna direction. The operation consists in pushing this holder against a fixed collar D surrounding the spindle; consequently a combination of the form of the holder and also of the cutter is transferred to the piece of wood.

In the Small Arm Factory at Enfield that intricate piece of mechanism, the gun stock, is produced entirely by machinery. It will be well understood how very difficult it is to make such articles perfect both in form and dimensions; it is comparatively easy to make things nearly correct, but to attain to perfect fitting from the machine involves conditions which are not ordinarily realised. With the machinery in question this absolute fit is secured at the rate of from 1000 to 1200 gun stocks per week, leaving only the exterior smoothing to be done by hand. The object of the present paper is not to describe the machines in detail, but only the principle of cutting; for it requires upwards of a dozen machines to produce a gun stock, each being differently arranged to suit its special operation; but the general principle in all is the same, and if understood maty be readily applied in an infinite variety of ways for the performance of other operations.

The cutting out is effected by means of a revolving bit or drill $\mathrm{E}$, as shown in Fig. 13, Plate 60, made in the required form and driven at a great velocity, 6000 revolutions per minute; this being kept very sharp is capable of producing a clean smooth hole, and if pushed against the wood $\mathbf{F}$ sideways, or the wood pushed against the drill, will cut its way in any direction. In order to guide the drill in cutting 
out the required shape, there is placed alongside the gun stock F a hard steel pattern $G$ of the required form; and upon the frame which carries the drill $\mathbf{E}$ there is fixed a dumb tracer $\mathrm{H}$ of the same external form as the drill. This tracer being connected with the same framework as the drill, and both having the same vertical or horizontal movements, it follows that if the tracer is brought into contact with the pattern $G$ the drill will be brought into contact with the wood $F$ and will drill its way accurately according to the truth with which the tracer is pushed round the pattern.

Owing to the intricate form of the gun lock, bits of different sizes are required to cut out the wood to fit it correctly: this is effected from a single pattern in the following manner. The machine is provided with a number of revolving bits of different dimensions, each accompanied by a tracer of exactly the same external form; and the machine is so constructed that each in succession can be brought into operation. At the commencement the larger bits are introduced; these clear out wherever the larger tracers can find an entrance into the pattern; and having done their part, the smaller bits are substituted, and at last a very delicate drill for touching off certain points too minute for its predecessors. Thus the whole operation is accomplished with the most rigid accuracy, and with a rapidity truly wonderful; for, including the fixing of the stock and the several changes of the drills, the whole may be performed under a minute.

The question naturally suggests itself, how can this accuracy be secured, seeing that the revolving drills are more liable to wear than the dumb tracers, and that such a condition must necessarily alter the dimensions of the recess produced by the drills, even if it give the proper shape. The method of compensating for wear is very ingenious and deserves to be generally known. The conical hole in the end of the running spindle into which the drills are fitted is made very slightly eccentric; the drill is also made eccentric on its shank to the same amount. Both the end of the spindle and the drill are graduated round the circumference. When the drill is new it is set to run truly central, by placing the two eccentricities opposite to each other, and thus to cut out its own diameter; but as by continued sharpening it necessarily wears, the time arrives when it requires to be altered in its 
position in the spindle, by throwing it slightly out of centre; and owing to the high velocity with which it revolves, any disadvantage arising from the eccentricity in the working is not perceptible, while the accuracy and correctness of the fit are rigidly maintained.

Mr. J. Anderson exhibited a series of specimens showing the course of manufacture of the wood linings for scabbards that had been described in the paper, and of the wood sabots for loading cannon.

Mr. B. Fothergill thought the paper was a very interesting and valnable communication, and the machines described were remarkably complete and perfect, and very well designed for the special purposes for which they were intended. He had also seen several very ingenious American machines for working wood, though not carried to the complete extent of those described in the paper, and they might no doubt be available in our workshops and were well deserving of careful attention. The earliest application he remembered of machinery for the purpose of working wood was an attempt made by Mr. Roberts many years since to facilitate the ornamenting of table legs by means of a revolving cutter at a high velocity brought to bear on different portions of the work successively; he had succeeded in the object, but was prevented from bringing the plan into use by the prejudice of the workmen who opposed the use of the machine. The next application of machinery was to the manufacture of sticks for umbrellas, by having a hollow spindle revolving in two uprights, and at the end of the spindle a suitable cutter revolving with it, and the stick was then simply pushed up through the hollow spindle, and was quickly rounded throughout at the rate of two sticks per minute.

Mr. W. FAirbairs, having been connected with the construction of the engines for driving the machinery described in the paper, had witnessed the excellence and efficiency of the machinery, which was certainly most admirably contrived, and for which they were indebted to the energy and skill that Mr. Anderson had brought to bear on the extended applications of machinery to various works in connexion with the public service. 
The Charrmax could add his testimony to the great benefits that had resulted in the Government workshops from the improvements in the machinery effected by Mr. Anderson, and the great increase of efficiency in the workshops, where there was much to be seen and learnt applicable to other kinds of artificer's work. He proposed a vote of thanks to Mr. Anderson for his lucid and interesting paper, which was passed, and expressed a hope that he would give them a further communication on the subject.

Mr. J. Anderson said he would be happy at a future time to present some descriptions of other machinery that would be interesting to the Institution.

The following Paper, by Mr. John Hosking, of Gateshead, was then read :- 
Fig.1. American Copying Lathe.

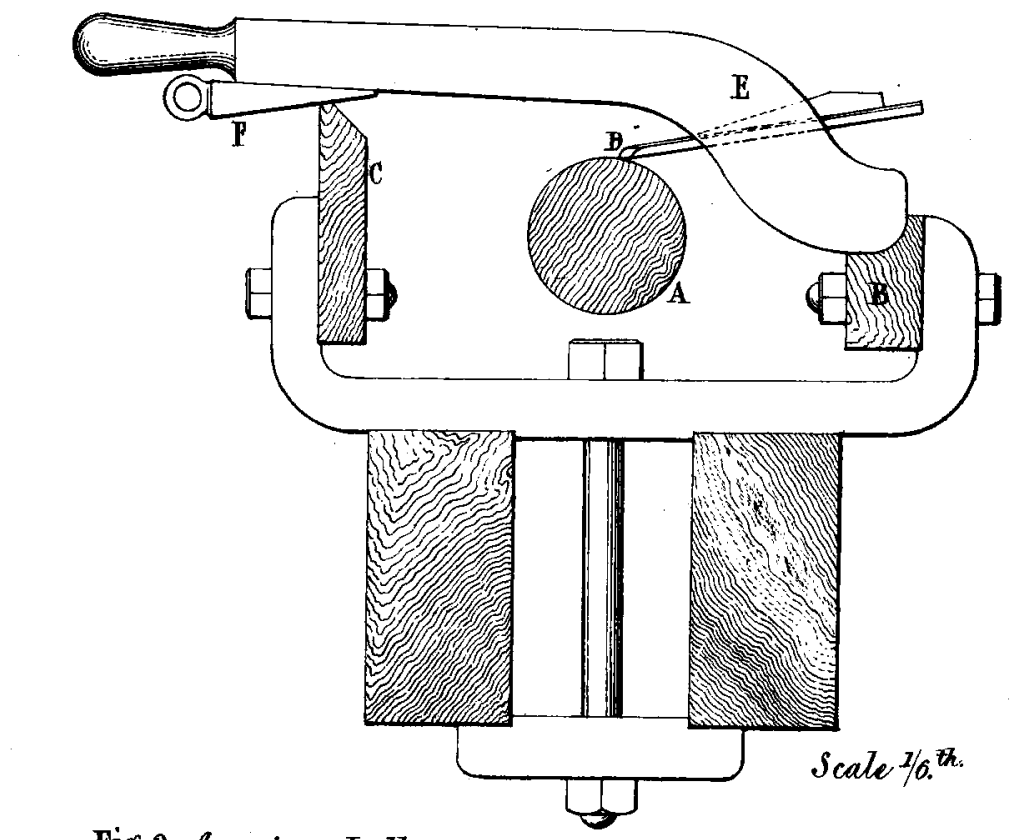

Fig. 2. American Lathe

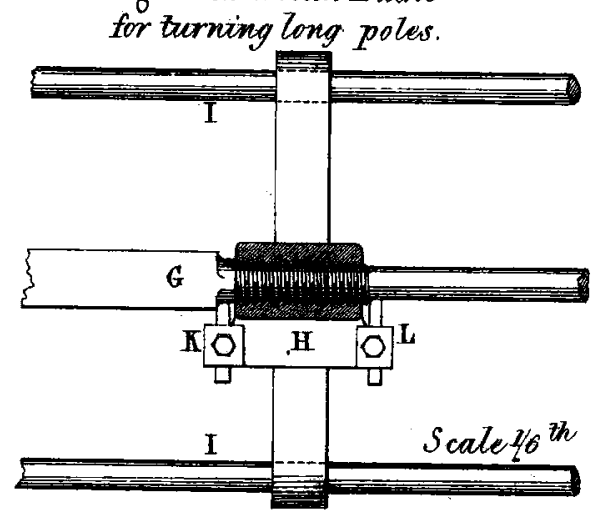

Fig.3. Lathe Centre for burning wood.

Fig.4.

Fig. 5. Augur and B oxo Chisel for square hotes.
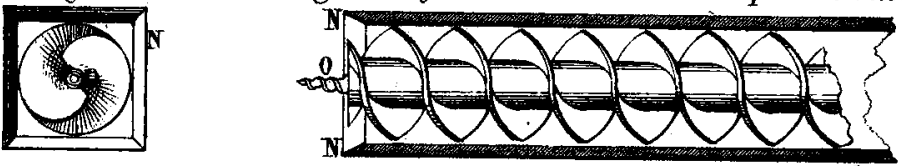

Scale $1 / 3$ rd $^{\text {rd }}$

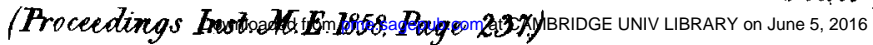


Fig.6. Latho for Turning Sabots.

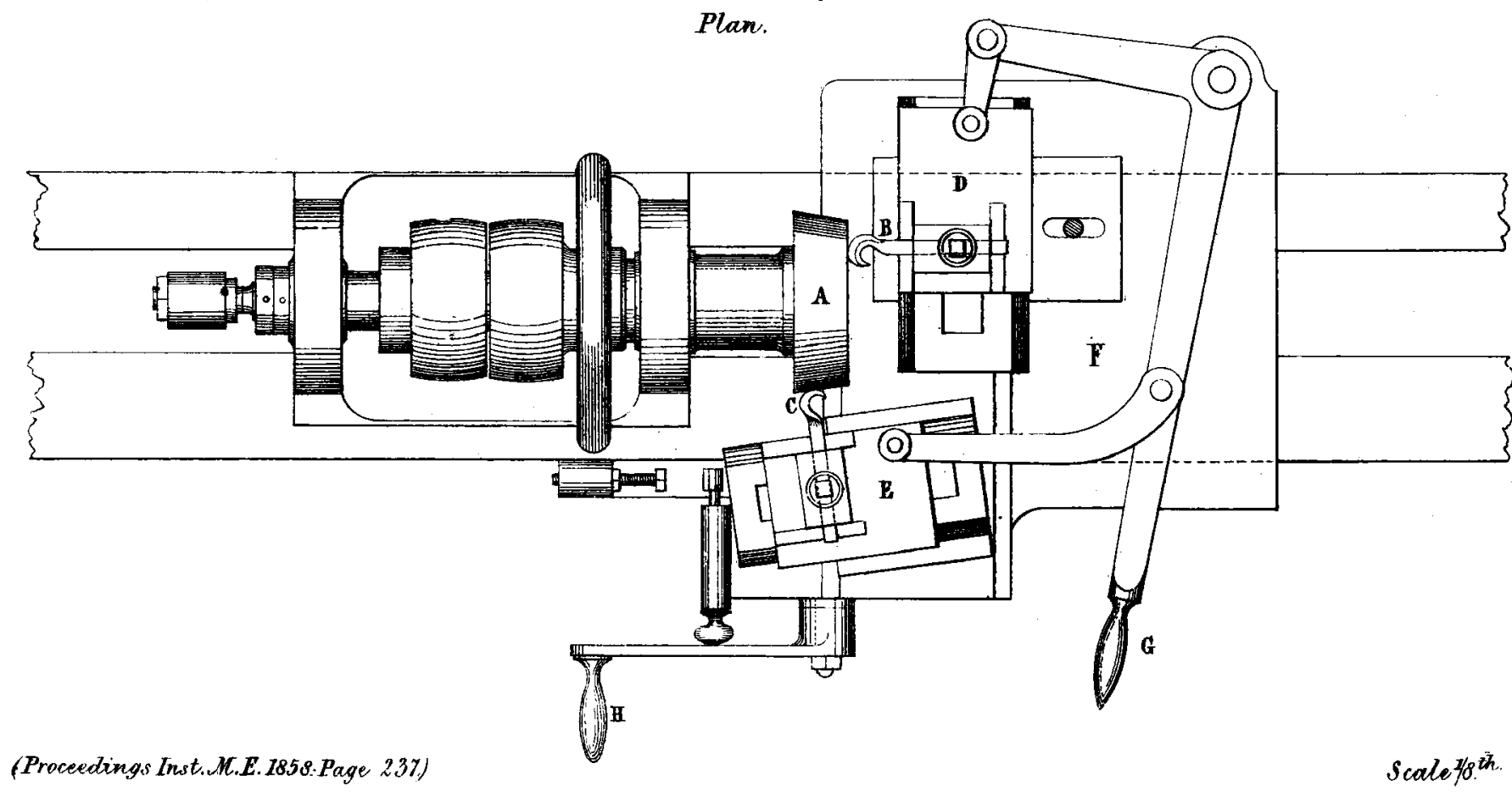


Fig.7. Lathe for Hollowing Sabots.

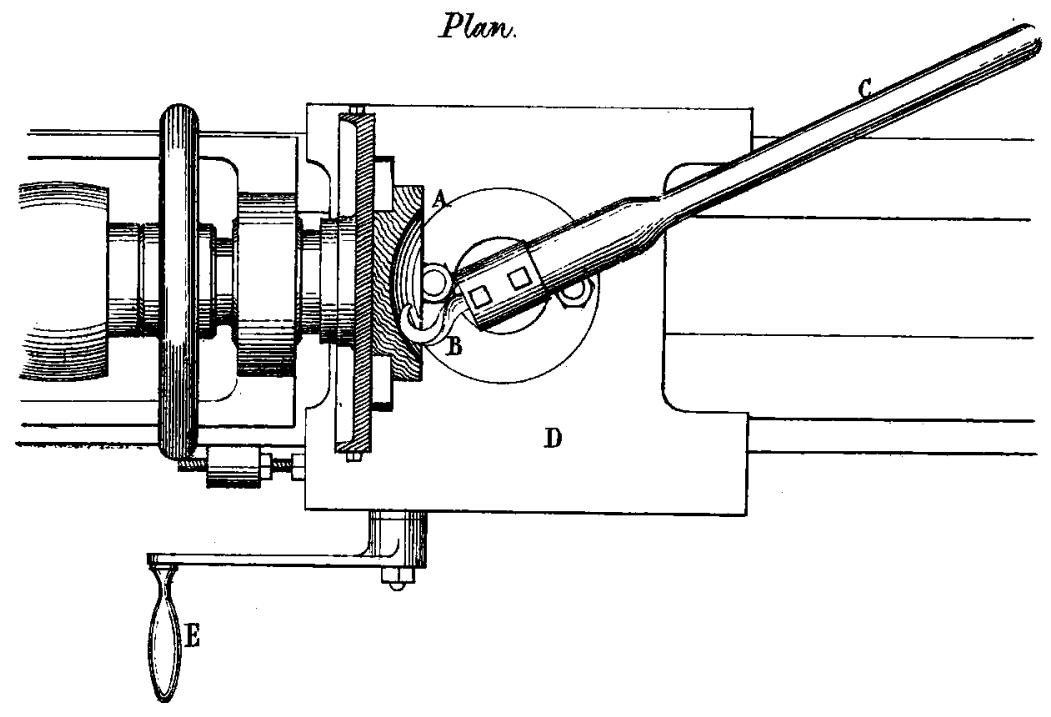

Fig.8. Blanchard Furning Lathe.

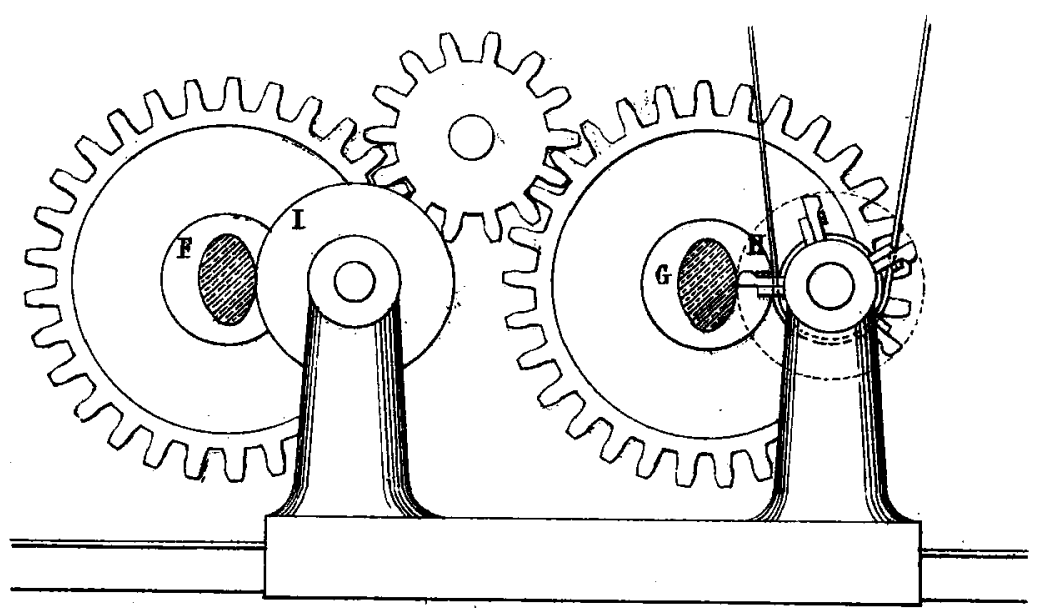

Scate $7 \% 8^{\text {th }}$ 
COPYING MACHINERY.
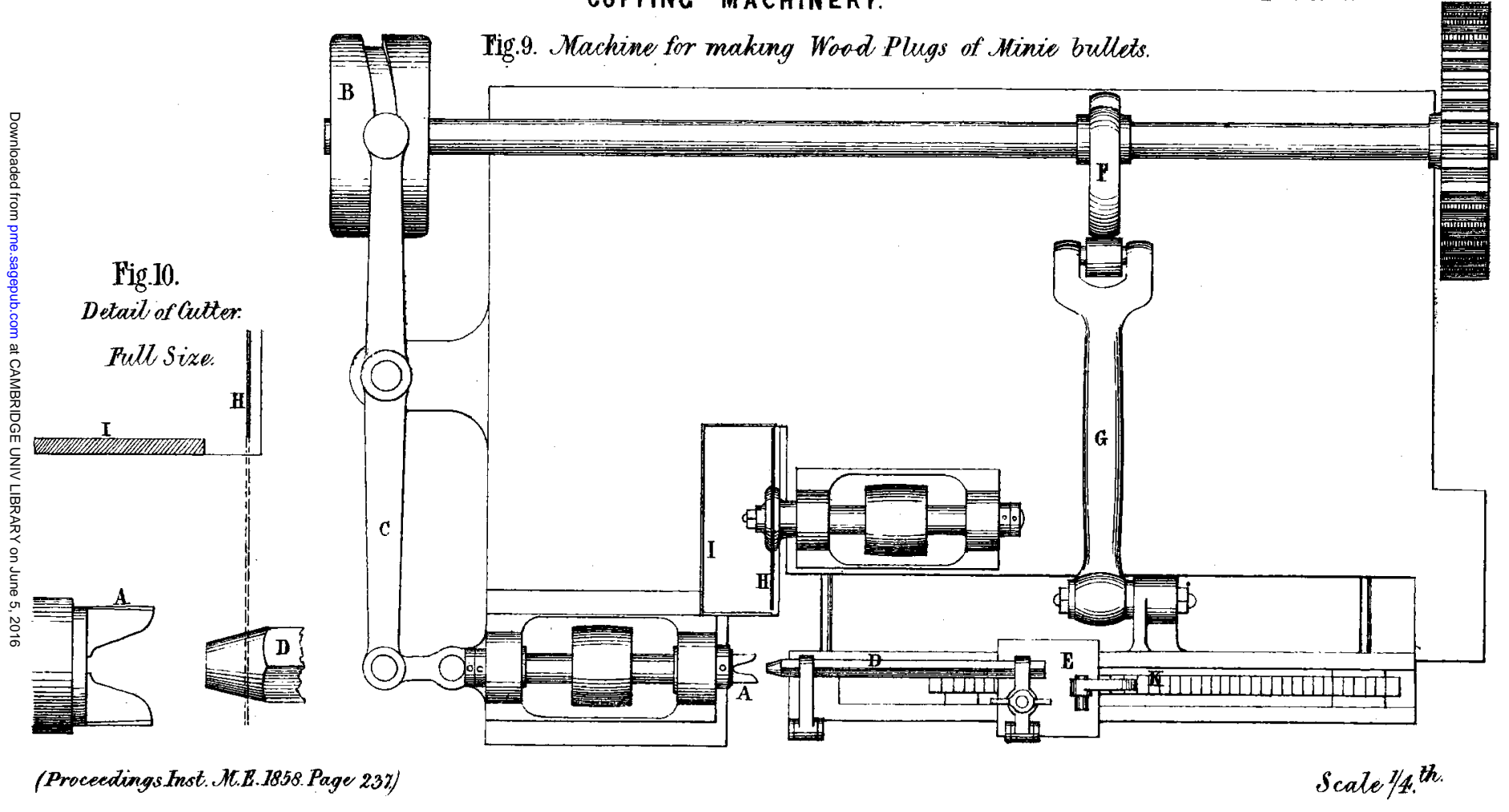

makng Wood Plugs of Ninic bullets. 
Fig.ll. Machine for Edye Mouldings.

Pig. 12. Plun.
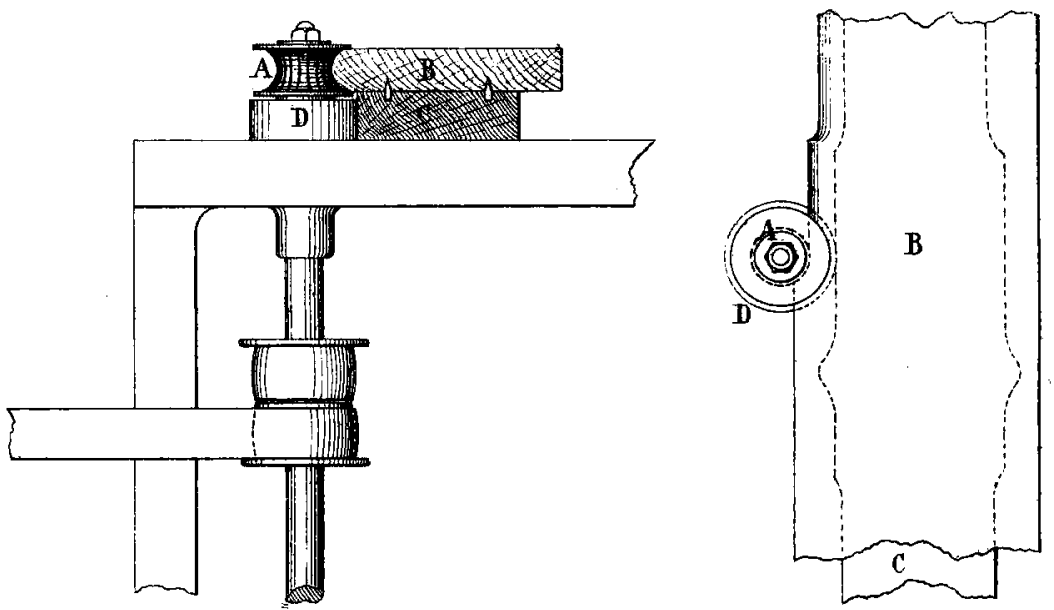

Fig:13. Machine for Gutting Gun Stocks.

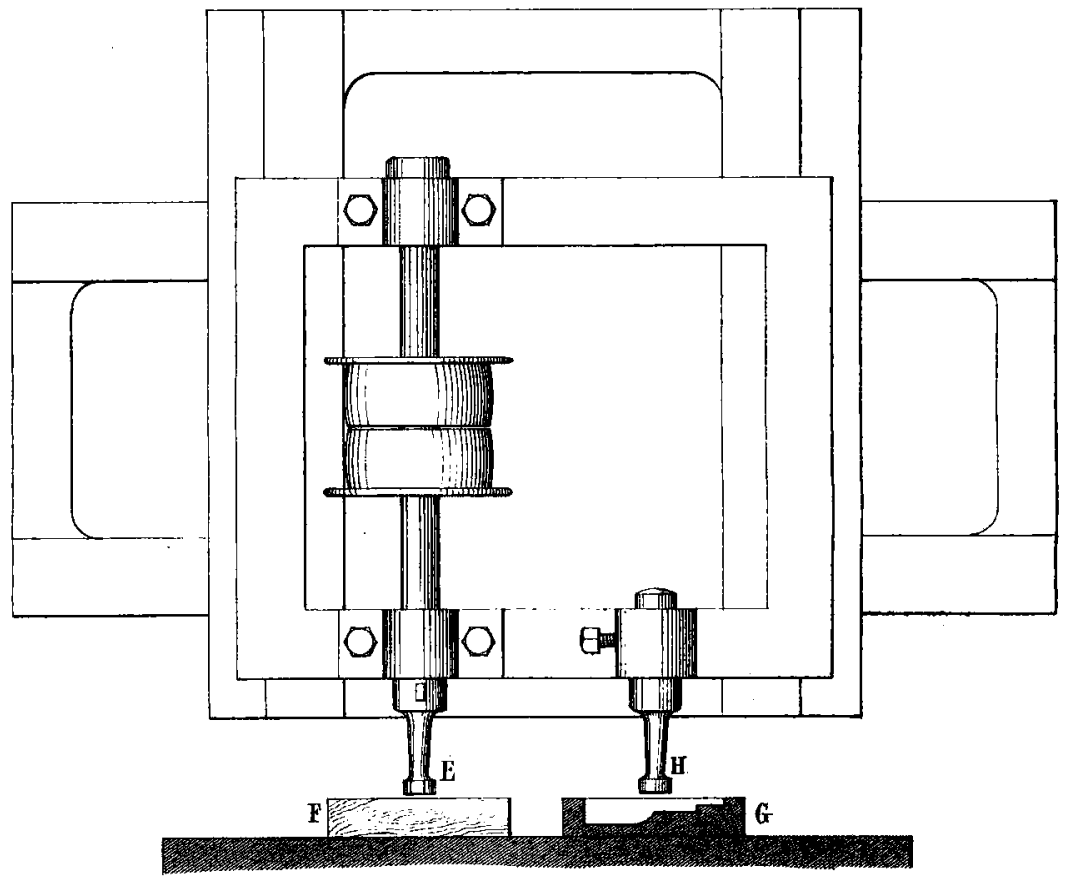

$S$ cale $14^{\text {th }}$. 